\title{
Blockade of Glutamate-Mediated Activity in the Developing Retina Perturbs the Functional Segregation of ON and OFF Pathways
}

\author{
Silvia Bisti, ${ }^{1,2}$ Claudia Gargini, ${ }^{1,3}$ and Leo M. Chalupa ${ }^{4}$ \\ 1/nstitute of Neurophysiology, Consiglio Nazionale delle Ricerche, Pisa 56127, Italy, ${ }^{2}$ Dipartimento di Scienze e Tecnologie \\ Biomediche, University of L'Aquila, L'Aquila 67100, Italy, ${ }^{3}$ Dipartimento di Psichiatria, Neurobiologia, Farmacologia, e \\ Biotechnologie, University of Pisa, Pisa, Italy, and ${ }^{4}$ Center for Neuroscience and Section of Neurobiology, Physiology and \\ Behavior, Division of Biological Sciences, Davis, California 95616
}

The dendrites of ganglion cells initially ramify throughout the inner plexiform layer of the developing retina before becoming stratified into ON or OFF sublaminae. This ontogenetic event is thought to depend on glutamate-mediated afferent activity, because treating the developing retina with the glutamate analog 2-amino-4-phosphonobutyrate (APB), which hyperpolarizes ON cone bipolar cells and rod bipolar cells, thereby preventing their release of glutamate, effectively arrests the dendritic stratification process. To assess the functional consequences of this manipulation, extracellular recordings were made from single cells in the A laminae of the dorsal lateral geniculate nucleus and from the optic tract in mature cats that had received intraocular injections of APB during the first postnatal month. Such recordings revealed that stimulation of the APB-treated eye evoked both ON as well as OFF discharges in $37 \%$ of the cells tested. (As expected, when the normal eye was activated, virtually all cells yielded only ON or OFF responses.) The proportion of ON-OFF cells found here corresponds closely to the incidence of multistratified dendrites observed previously in anatomical studies of APB-treated cat retinas. This suggests that the ganglion cells with multistratified dendrites receive functional inputs from $\mathrm{ON}$ as well as OFF cone bipolar cells. This interpretation is further supported by the finding that the proportion of ON-OFF cells was very similar in the geniculate layer innervated by the treated eye and in the optic tract. The cells activated by the APB-treated eye were also found not to show response suppression when flashing stimuli of increasing size were used. This suggests that exposing the developing retina to APB perturbs the neural circuitry mediating the antagonistic center-surround organization found in normal receptive fields. The functional changes evident after treating the developing retina with APB suggest that it should now be feasible to assess how the segregation of ON and OFF retinal pathways relates to organizational features at higher levels of the visual system, such as orientation selectivity in cortical cells.

Key words: inner plexiform layer; ON/OFF responses; dorsal lateral geniculate nucleus; retina; ganglion cells
In the vertebrate retina, the dendrites of most ganglion cells are stratified into two distinct sublaminae of the inner plexiform layer (IPL). Retinal ganglion cells with dendrites ramifying proximal to the soma are activated by increments of light, whereas ganglion cells with distal dendrites respond to light decrements (Famiglietti and Kolb, 1976; Nelson et al., 1978). This functional distinction reflects the fact that the dendritic processes in the two sublaminae of the IPL are differentially innervated by bipolar cells that either depolarize or hyperpolarize on exposure to light. Such an organization provides the structural basis for the segregation of ON and OFF retinal pathways (for review, see Wässle and Boycott, 1991). Moreover, in some species such as the tree shrew, ferret, and mink, ON and OFF channels remain segregated within different sublaminae of the dorsal lateral geniculate nucleus (dlgn) as well as in layer 4 of the visual cortex (Stryker and Zahs, 1983; Norton et al., 1985; Conway and Schiller, 1993).

The formation of segregated ON and OFF retinal pathways involves the gradual restriction of initially multistratified ganglion

\footnotetext{
Received Feb. 9, 1998; revised April 13, 1998; accepted April 22, 1998.
}

This work was supported by National Institutes of Health Grant EYO3391, National Science Foundation Grant IBN12593, the Fogarty International Center, and NATO. We thank Paolo Martini and Mario Pirchio for computer software, Daniela Morconi for animal care, and Julio Cappagli for technical assistance.

Correspondence should be addressed to Leo M. Chalupa, Section of Neurobiology, Physiology, and Behavior, University of California, Davis, CA 95616.

Copyright (C) 1998 Society for Neuroscience $0270-6474 / 98 / 185019-07 \$ 05.00 / 0$ cells (Maslim and Stone, 1986, 1988; Bodnarenko and Chalupa, 1993; Bodnarenko et al., 1995). This process takes place relatively late in development so that in the newborn cat retina $\sim 40 \%$ of the ganglion cells are still in their immature, multistratified state (Bodnarenko et al., 1995). Moreover, the restriction of dendrites into $\mathrm{ON}$ and OFF sublaminae of the IPL occurs during the time when bipolar cells establish synaptic contacts with ganglion cells (Maslim and Stone, 1986, 1988). Such a temporal coincidence suggested the possibility that synaptic events within the IPL could provide a signal for the retraction of initially multistratified processes. This hypothesis was tested recently by treating the developing cat retina with the glutamate analog 2-amino-4phosphonobutyrate (APB) (Bodnarenko and Chalupa, 1993; Bodnarenko et al., 1995). This drug hyperpolarizes ON cone bipolar cells as well as rod bipolar cells, thereby preventing their release of glutamate (Slaughter and Miller, 1981; Muller et al., 1988; Euler et al., 1996). Daily treatment with APB from postnatal day 2 (P2) to P12 was found to prevent the stratification of ganglion cell dendrites into ON and OFF sublaminae of the IPL. Interestingly, earlier studies had reported that neither blockade of action potentials by intraocular injection of TTX (Dubin et al., 1986; Wong et al., 1991) nor dark rearing (Leventhal and Hirsch, 1983; Lau et al., 1990) affects the normal incidence of stratified ganglion cells. Taken together, the available evidence lends support to the idea that glutamate-mediated afferent activity plays a 
role in the stratification of ganglion cell dendrites, resulting in the segregation of ON and OFF retinal pathways.

The functional consequences of arresting the dendritic stratification of retinal ganglion cells by treating the developing retina with APB remains to be established. One possibility is that the multistratified ganglion cells respond to flashing spots of light with either ON or OFF discharges, as is the case in the normal retina. This would imply that bipolar cell innervation patterns are not altered appreciably, so that ON or OFF bipolar cells selectively innervate a given multistratified ganglion cell. Alternatively, there could be an abnormally high proportion of ganglion cells responding to flashing stimuli with $\mathrm{ON}-\mathrm{OFF}$ discharges. The presence of such neurons would suggest that multistratified ganglion cells in the APB-treated eye receive functional synaptic inputs from $\mathrm{ON}$ as well as OFF bipolar cells. To distinguish between these possibilities, intraocular injections of APB were made in cats during the first postnatal month. Responses to flashing spots of light were subsequently assessed when these animals reached maturity by means of extracellular recordings from the optic tract (OT) and the A laminae of the dorsal lateral geniculate nucleus.

Some of our findings have been summarized in abstract form (Gargini et al., 1996).

\section{MATERIALS AND METHODS}

Experiments were performed on six cats obtained from an in-house colony. Four of the animals received unilateral intraocular injections of APB during the first postnatal month, and two were normal controls. All procedures were in compliance with National Institutes of Health guidelines and approved by the Animal Care and Use Committee of the Consiglio Nazionale delle Ricerche.

Intraocular injections. APB was injected into the right eyes of newborn cats at P2 and continued daily until P32, with a $2 \mathrm{~d}$ respite for the weekends. The animals were anesthetized with $4 \%$ halothane in oxygen, and intraocular injections were made with a $10 \mu$ l syringe, containing $0.092 \mathrm{mg}$ of APB diluted in sterile saline, and a 28 gauge needle. This dosage is the same as that used in previous electrophysiological and anatomical studies (Slaughter and Miller, 1981; Bodnarenko et al., 1995). The injections were made into the temporal portion of the sclera at the level of the ora serrata, and great care was taken to insert the needle through the initial opening for all subsequent injections. After the last injection at P32, the animals were allowed to reach maturity in the colony.

Animal preparation for recordings. When an animal was at least 4 months of age, it was used for the electrophysiological experiments. Anesthesia was initially induced by an injection of ketamine (Ketalar; Parke-Davis, Courbevoie, France; $30 \mathrm{mg} / \mathrm{kg}$, i.m.), and an endotracheal tube and venous cannula were inserted. During surgery and throughout the recording session, anesthesia was maintained by Farmotal (sodium thiopental, Famitalia; $1.5 \mathrm{mg} \cdot \mathrm{kg}^{-1} \cdot \mathrm{hr}^{-1}$ ) delivered intravenously. Bilateral openings were made in the skull to allow insertion of microelectrodes into the dlgn and the OT, contralateral and ipsilateral to the treated eye. After infiltration of exposed tissue with local anesthetic (Novocain), paralysis was induced with intravenal infusion of Pavulon (pancuronium bromide, $0.2 \%$; Organon Teknika Cappel, Durham, NC; $0.1-0.2 \mathrm{ml} \cdot \mathrm{kg}^{-1} \cdot \mathrm{hr}^{-1}$ ), and the animal was artificially ventilated to maintain expired $\mathrm{CO}_{2}$ at 4.0-4.2\%. Both EEG and ECG were monitored continuously to assess the adequacy of the anesthesia and the general condition of the animal. Body temperature was also monitored and maintained at $38^{\circ} \mathrm{C}$ with an electric heating pad. The pupils were dilated with atropine sulfate $(0.5 \%)$, and the corneas were protected by contact lenses with artificial pupils of $3 \mathrm{~mm}$ diameter. The refraction of the eye was determined by means of retinoscopy and corrected with appropriate spectacle lenses placed in front of the eye. The positions of the papilla and area centralis were determined at the beginning of the experiment and were checked periodically.

Electrophysiological recordings. Single-unit recordings were made from cells in laminae A and A1 of the dlgn, using a micropipette filled with $\mathrm{NaCl}(3 \mathrm{M})$ and fibers in the OT with tungsten microelectrodes. When the action potentials of a single cell were isolated from background activity, the unresponsive eye was covered, and the position of the receptive field was plotted on a tangent screen using slits or spots of light. Responses of the cell were assessed by flashing stimuli in a region of the visual field corresponding to the receptive field of the cell. This region was subdivided into separate elements (usually between 9 and 25) of equal size in which the luminance was locally modulated in time either sinusoidally or in a square-wave manner. The computer program sampled each element in the stimulus matrix according to a linear or random sequence, allowing for a recovery time between successive modulations during which the entire field remained at mean luminance. For each element in the matrix, light was modulated at a frequency of $1-10 \mathrm{~Hz}$ for at least 10 periods. The responses of the cell triggered by the modulation frequency were conventionally amplified and displayed on an oscilloscope. For quantitative analyses, each action potential triggered a standard pulse from a window discriminator that was sent to a computer for storage and analysis. The mean luminance of the field was $28 \mathrm{~cd} / \mathrm{m}^{2}$, and the amplitude of modulation was always maintained at $100 \%$. The sinusoidal or square-waves were rectified to obtain stimuli reversed in contrast. Stimuli above and below background were generated by the VSG2/3 computer graphics card (Cambridge Research Systems) displayed on the face of a Barco CDCT6551 color monitor at a frame rate of $120 \mathrm{~Hz}$ with $512^{2}$ pixel spatial definition and 14 bits per color per pixel. The acquisition system was synchronized with the temporal frequency of each stimulus to provide peristimulus time histograms and corresponding rasters depicting individual response epochs.

After recordings were completed on one side of the brain, a pressure injection of horseradish peroxidase was made into the dlgn and OT before recordings were made from these structures on the other side. At the end of all recordings, the animal was administered a lethal dose of barbiturate and perfused transcardially with solutions appropriate for peroxidase histochemistry. The retinas were removed and processed for an anatomical investigation (S. Bisti, S. Deplano, C. Gargini, and L. M. Chalupa, unpublished observations).

\section{RESULTS}

The results are based on recordings from 113 cells: 73 from the dlgn and 40 from the OT. Thirty-five of the cells responded to stimulation of the normal eye (23 dlgn and 12 OT), whereas 78 cells were activated by the APB-treated eye (50 dlgn and 28 OT). Cells were classified on the basis of their responses to a flashing stimulus centered on the receptive field with the size of the spot chosen to evoke clear and reliable responses. When the normal eye was stimulated, all but one of the neurons discharged to either the onset or the offset of a flashing stimulus. The atypical cell, encountered in the dlgn within layer A1, discharged to both stimulus onset as well as offset. In all other cases, the response properties of the units activated by the normal eye changed in a predictable manner when the contrast of the stimulus shifted from above to below background levels. Thus, cells that yielded ON discharges to bright spots produced OFF responses of approximately equal magnitude when dark spots were used.

By contrast, stimulation of the APB-treated eye produced ONOFF discharges in $37 \%$ of the neurons tested (Fig. 1), and such cells were encountered at about the same frequency within the OT (9 of 28) as in the dlgn (20 of 50). In all these cases, ON-OFF discharges were evident when flashing stimuli were above as well as below background levels. Figure 2 shows two examples of such $\mathrm{ON}-\mathrm{OFF}$ cells, one recorded from the optic tract $(A)$ and the other from the dlgn $(B)$. Also illustrated are the responses of a third neuron $(C)$ that yielded only $\mathrm{ON}$ discharges to stimulation of the APB-treated eye in a manner indistinguishable from a normal response pattern.

Because our goal was to sample the response patterns of as many cells as possible, we did not perform the battery of tests required to distinguish between different classes of cells (e.g., $\mathrm{X}$ and Y). However, there was no indication that the ON-OFF cells differed in terms of response briskness or receptive field size from the overall sample; moreover, such units were characterized by 


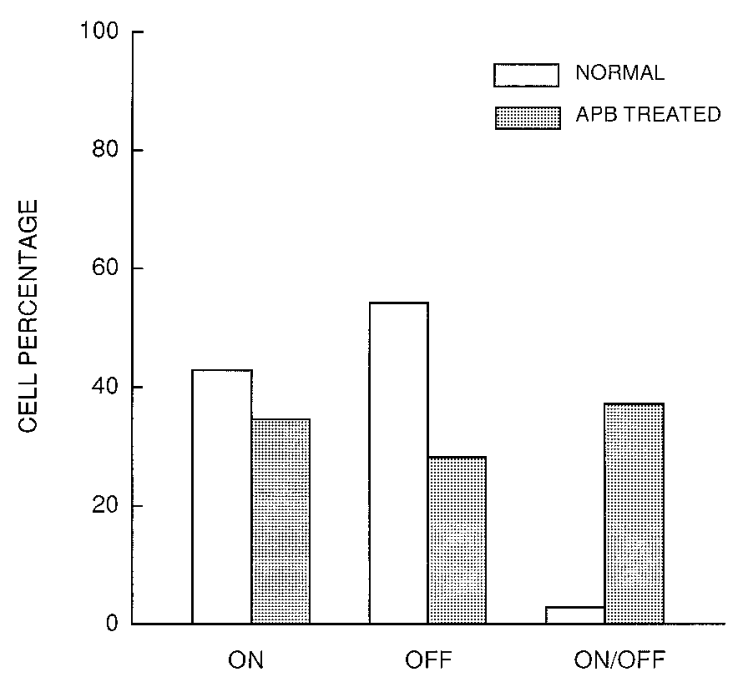

Figure 1. Percentage of $\mathrm{ON}, \mathrm{OFF}$, and $\mathrm{ON}-\mathrm{OFF}$ cells in response to stimulation of the normal eye (open columns, $n=35$ ) and the APBtreated eye (shaded columns, $n=78$ ). The proportions of ON-OFF cells encountered in recordings from the OT $(32.1 \%)$ and the dlgn $(40 \%)$ were similar, so the data have been combined in the histograms for purposes of clarity.

sustained as well as transient discharge patterns. Thus, most likely the ON-OFF cells we recorded encompassed more than one cell class, but the proportion of the different cell classes manifesting such discharge patterns remains to be established.

In 15 units that yielded $\mathrm{ON}-\mathrm{OFF}$ discharges to stimuli centered on the receptive field (nine dlgn and six OT), we also assessed responses to small flashing spots positioned within different regions of the receptive field. In five of these cells (three dlgn and two OT) the response pattern was the same (i.e., $\mathrm{ON}-\mathrm{OFF}$ ) irrespective of the position of the stimulus in the receptive field, although response magnitude did vary with stimulus position. An example of one such cell showing relatively uniform spatial responsivity is depicted in Figure 3.

In 10 other cells tested in the same manner (six dlgn and four $\mathrm{OT}$ ), there were pronounced variations in discharge patterns with stimulus position. In the example shown in Figure 4, the cell yielded ON-OFF discharges when the stimulus was in the upper left, middle, and lower right positions of the receptive field, but only ON responses were evoked at other stimulus positions. This neuron, and all other cells exhibiting such a patchy spatial organization, manifested clear $\mathrm{ON}-\mathrm{OFF}$ discharge patterns to large flashing stimuli covering the entire region of the receptive field sampled by the smaller stimuli (Fig. 4B).

The receptive field properties of the cells driven by the APBtreated eye also differed from normal in their responses to stimuli of increasing size. A common feature of these neurons was that they did not show response suppression. This is illustrated in the series of peristimulus time histograms (PSTHs) depicted in Figure $5 A-C$ for three ON-OFF cells. In each case, the magnitude of the response can be seen to increase with stimulus size. There were differences, however, in the manner that responses changed with stimulus size. In Figure $5 A$, an $\mathrm{ON}-\mathrm{OFF}$ discharge pattern of increasing magnitude is evident as the size of the stimulus increased. This pattern was found in the majority of cells (13 of 16). In the remainder of the neurons (3 of 16), responsivity also increased when the stimulus was increased in size, but in these cells the response pattern was found to vary as a function of
A
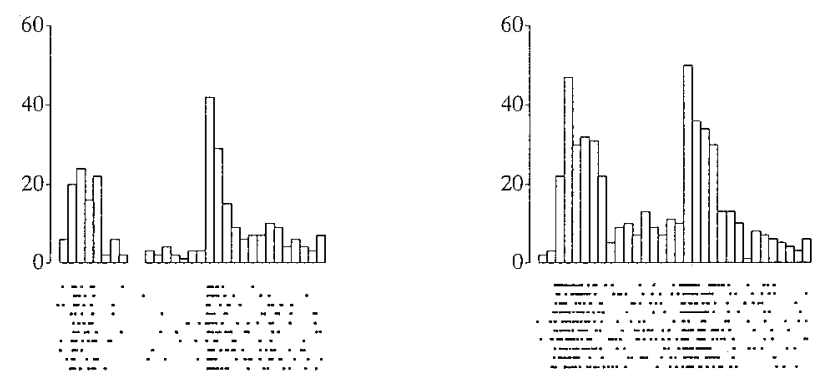

B
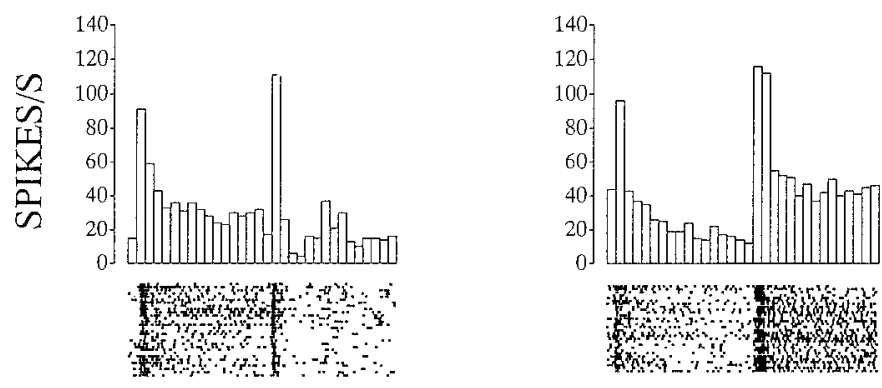

C
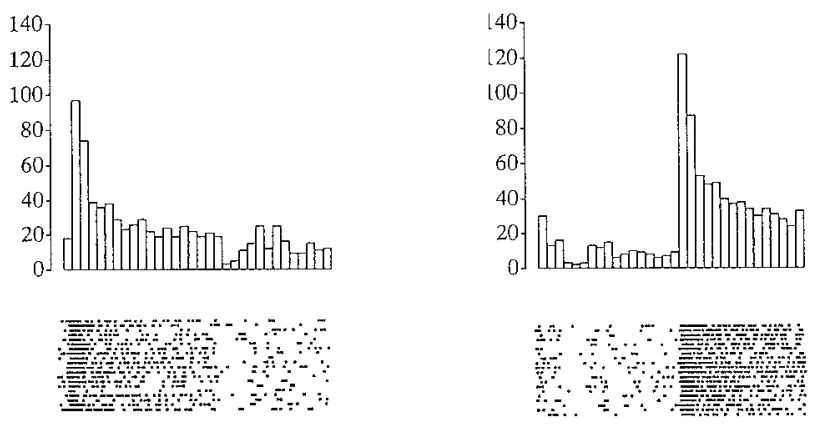

Figure 2. PSTHs and response rasters for three neurons in response to stimulation of the APB-treated eye. $A$, ON-OFF cell isolated in the OT (10 stimulus presentations of a $2^{0}$ diameter spot). $B$, ON-OFF cell isolated in layer $\mathrm{A}$ of the dlgn (30 stimulus presentations of a $1^{0}$ spot). $C$, ON cell in layer A of the dlgn ( 18 stimulus presentations of a $2.5^{\circ}$ spot). The light stimulus was modulated at $1 \mathrm{~Hz}$ by a half-wave rectified sinusoid above (left panels) or below (right panels) the mean luminance $\left(28 \mathrm{~cd} / \mathrm{m}^{2}\right)$. The contrast was $100 \%$, and the time bin was $31.3 \mathrm{msec}$.

stimulus size. In the cell shown in Figure $5 B$, an ON discharge is apparent with the smallest stimulus, whereas $\mathrm{ON}-\mathrm{OFF}$ responses are evident with large stimuli. In Figure $5 C$, the two smaller stimuli elicited weak ON-OFF responses, but with the largest stimulus a robust OFF discharge can be seen. The receptive field locations of the three cells manifesting changes in response pattern did not differ from the overall sample of cells. Such variations in response pattern with stimulus size might relate to the spatial organization of receptive fields described above (Fig. 4), but this remains to be established.

Interestingly, the cells that responded to stimulation of the APB-treated eye with only ON or OFF discharges also showed no evidence of a suppressive surround in their receptive fields. This was found in every cell tested with stimuli of increasing size $(n=16)$. Examples of the response properties of two such cells, one $\mathrm{ON}$ and the other OFF, are shown in Figure 6, $A$ and $B$, 


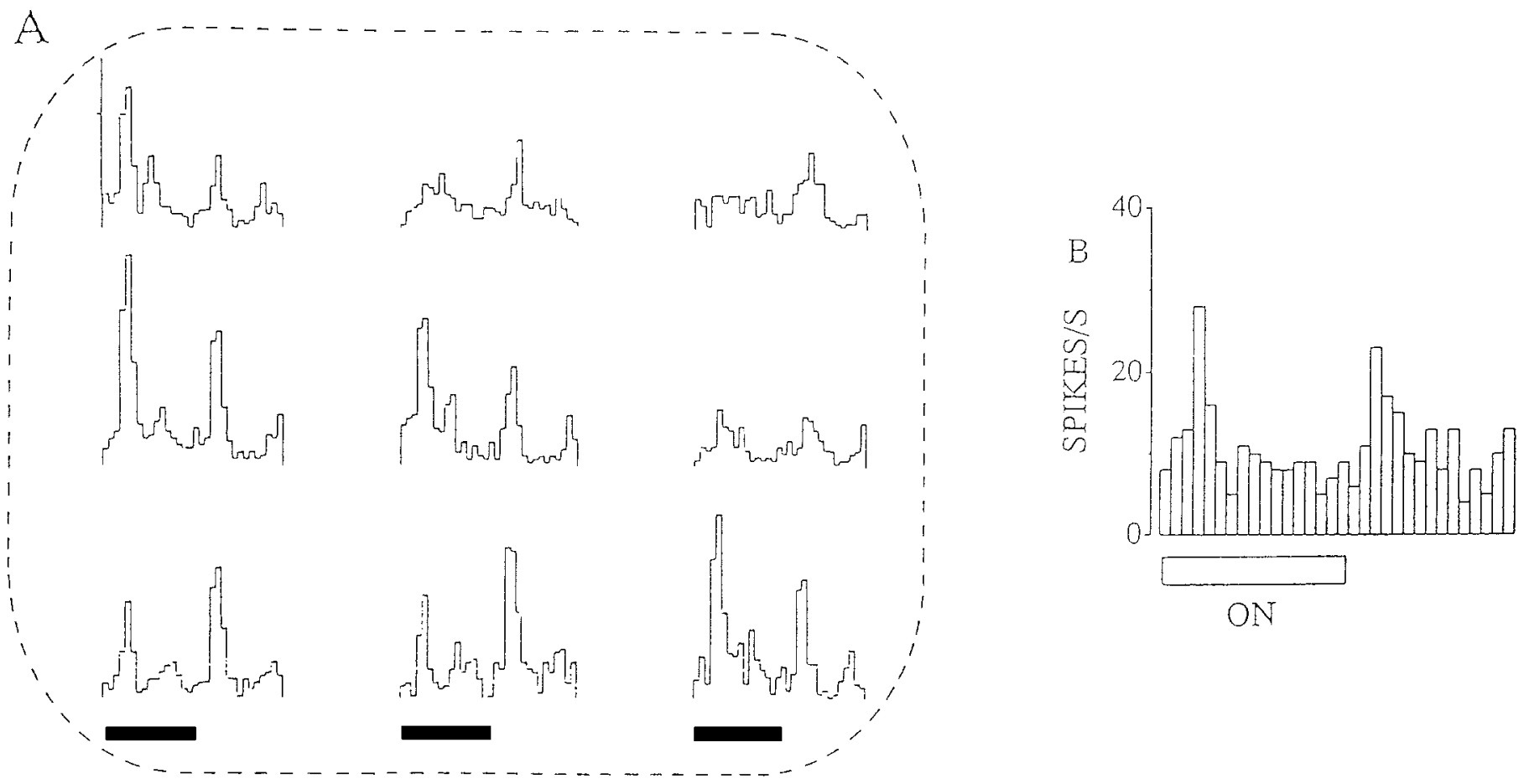

Figure 3. Uniform spatial organization within the receptive field. $A$, PSTHs recorded at nine different positions within the receptive field of an ON-OFF cell isolated in dlgn, lamina A, to 24 stimulations of the APB-treated eye. Note that ON-OFF discharges were obtained at all stimulus positions, except at the top right position, which was outside the responsive region. The stimulus was a $1.4^{0}$ spot modulated at $2 \mathrm{~Hz}$ by a half-wave rectified sinusoid below the mean luminance, indicated by filled bars. $B$, PSTHs to a larger stimulus $\left(3^{0}\right.$ spot $)$ centered on the receptive field. In this case, the stimulus was modulated at $2 \mathrm{~Hz}$ by a half-wave rectified sinusoid above the mean luminance of $28 \mathrm{~cd} / \mathrm{m}^{2}$ (open horizontal bar). Contrast was $100 \%$, and the time bin $15.2 \mathrm{msec}$.

respectively. For comparative purposes, Figure $6 C$ depicts the responses of a cell to stimulation of the control eye demonstrating the normal decrease in responsivity when the dimensions of the flashing stimulus exceeded the receptive field center.

\section{DISCUSSION}

In the mature cat retina, ganglion cells respond to flashing stimuli centered on their receptive fields with either ON or OFF discharge patterns (Kuffler, 1953). This fundamental feature of visual processing relates to the stratification pattern exhibited by these neurons: cells with dendrites stratifying distal to the soma respond to light decrements, whereas those with proximal dendrites are activated by light increments (Famiglietti and Kolb, 1976; Nelson et al., 1978). By contrast, early in development the dendrites of retinal ganglion cells ramify throughout the IPL. In the cat retina, such stratification of dendrites begins $\sim 2$ weeks before birth and continues throughout the first postnatal month. This process can be perturbed by treating the developing retina with the glutamate analog APB (Bodnarenko and Chalupa, 1993; Bodnarenko et al., 1995), which hyperpolarizes ON-cone and rod bipolar cells (Slaughter and Miller, 1981; Bolz et al., 1984; Muller et al., 1988). Thus, after short-term APB treatment, the dendrites of $\sim 40 \%$ of the cells remain multistratified. An almost identical proportion of ON-OFF cells was found in the present study when the APB-treated eye was activated by flashing stimuli. Taken together, these observations suggest that nearly all of the multistratified dendrites in the APB-treated retina are innervated by $\mathrm{ON}$ as well as OFF bipolar cells and that both sets of interneurons form functional synapses.

The present study also reveals that treating the developing retina with APB throughout the first postnatal month has relatively long-term consequences. Our recordings were made several months after such treatments were discontinued, yet the incidence of ON-OFF discharges was virtually the same as the proportion of multistratified cells found in the postnatal cat retina that sustained short-term treatment with APB (Bodnarenko and Chalupa, 1993; Bodnarenko et al., 1995). Moreover, in the earlier study, we showed that when short-term treatment of APB was discontinued, the dendritic stratification process was found to resume, so that by 3 months of age the normal incidence of stratified ganglion cells was apparent. Thus, whereas the effects of short-term APB treatment appear to be entirely reversible, treating the developing retina for a longer period (the first postnatal month) alters functional organization into adulthood. Although we have yet to determine the proportion of multistratified cells in the retinas of the animals from which recordings were made, preliminary observations indicate that the incidence of such neurons is abnormally high in these retinas (Bisti, Deplano, Gargini, and Chalupa, unpublished observations).

\section{Convergence of bipolar cells in APB-treated retinas}

Recordings were made from both the OT and the dlgn, and in both structures the proportion of $\mathrm{ON}-\mathrm{OFF}$ cells was found to be essentially the same. Most likely, this outcome reflects the convergence of $\mathrm{ON}$ and $\mathrm{OFF}$ bipolar cells onto multistratified ganglion cell dendrites in the APB-treated retinas. Recordings limited only to the geniculate would not have allowed such an inference, because we could not have ruled out the possible convergence of $\mathrm{ON}$ and $\mathrm{OFF}$ retinal fibers onto geniculate neurons within the A layers. Such an abnormal innervation pattern is 


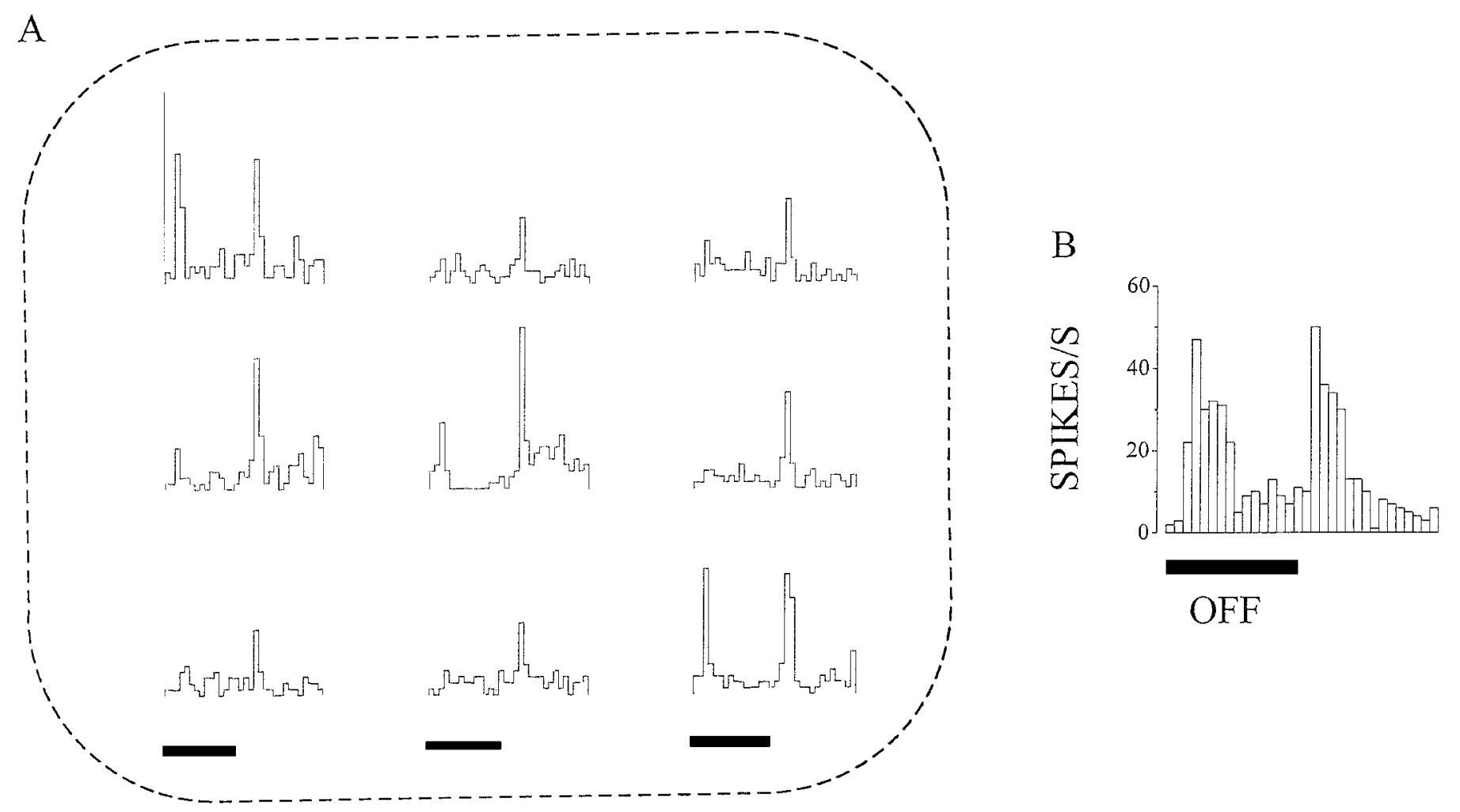

Figure 4. Patchy spatial organization within the receptive field. $A$, PSTHs to a $2^{0}$ spot at nine stimulus positions within the receptive field of an OT cell showing a patchy internal organization when the APB-treated eye was activated. $B$, ON-OFF responses in the same cell to a $6^{0}$ spot covering the entire receptive field. In all cases, the PSTHs are based on 10 stimulus presentations, and the stimulus was modulated at $2 \mathrm{~Hz}$ by a half-wave rectified sinusoid below the mean luminance (indicated by the filled bar). Mean luminance, $28 \mathrm{~cd} / \mathrm{m}^{2}$; contrast, $100 \%$; and time bin, $15.2 \mathrm{msec}$.

thought to occur after treatment of the developing cat retina with TTX (Dubin et al., 1986). It is also the case that some W cells (which innervate only the C-laminae of the dlgn) respond to flashing spots of light with ON-OFF discharges (Stone and Fukuda, 1974). Thus, recordings limited to the OT would be subject to the concern that the presence of an abnormally high number of ON-OFF cells could have reflected a high sample of W fibers from the treated eye. We did not encounter neurons with such properties in our OT recordings from normal animals. This was probably attributable to the fact that our electrodes were not suitable for isolating the thin-caliber W-cell fibers. Thus, our finding that the proportion of ON-OFF cells was similar in the OT and dlgn can only be interpreted as reflecting a convergence of $\mathrm{ON}$ and $\mathrm{OFF}$ bipolar cells onto ganglion cells with multistratified dendrites.

There are two means by which APB treatment of the developing retina could result in a high incidence of $\mathrm{ON}-\mathrm{OFF}$ ganglion cells. One possibility is that, during normal development, the dendrites of the multistratified cells could be transiently innervated by the axon terminals of ON as well as OFF bipolar cells. If this was the case, APB treatment might simply arrest such immature retinal circuitry, resulting in ganglion cells with $\mathrm{ON}-\mathrm{OFF}$ responses at maturity. The alternative scenario is that either $\mathrm{ON}$ or OFF bipolar cells selectively innervate the multistratified dendrites of individual ganglion cells, and APB treatment then induces the ingrowth of bipolar cells of the opposite response polarity. One way to differentiate between these two possibilities is to assess the incidence of ON-OFF ganglion cells in the developing retina when many cells are still in their immature state. In the former case, one would expect a high incidence of
$\mathrm{ON}-\mathrm{OFF}$ responding ganglion cells, whereas in the latter, the prevalence of such neurons in the developing retina should be no greater than at maturity.

\section{Functional state of developing retinal ganglion cells}

Extracellular recordings from ganglion cells in the newborn cat retina have been made by Tootle (1993), using an eyecup preparation. He found no evidence for $\mathrm{ON}-\mathrm{OFF}$ cells, suggesting that early in development the dendrites of multistratified ganglion cells are selectively innervated by either ON or OFF bipolar cells, but not by both sets of interneurons. This provides support for the instructional model proposed to explain how glutamate-mediated afferent activity might act to regulate dendritic stratification (Bodnarenko et al., 1995, their Fig. 8). The model postulates an asymmetrical distribution of synaptic inputs favoring either distal or proximal dendrites of initially multistratified ganglion cells so that during normal development, activity-mediated afferent inputs would "instruct" immature neurons which dendritic process to retract and which to maintain. It was hypothesized that blocking such afferent inputs by APB causes an arrest of dendrites in their multistratified state. Taken together, the results of the present study and the findings of Tootle (1993) suggest that APB treatment induces bipolar cell innervation onto multistratified dendrites (i.e., the second of the two alternatives discussed above). The fact that many cells driven by stimulation of the APB-treated eye showed a "patchy" organization in their receptive fields could reflect a nonuniform pattern of such ingrowth. It is also possible that some segment of the multistratified dendrites may have retracted in the APB-treated retinas. The resolution of this issue requires a careful morphological assessment of the 

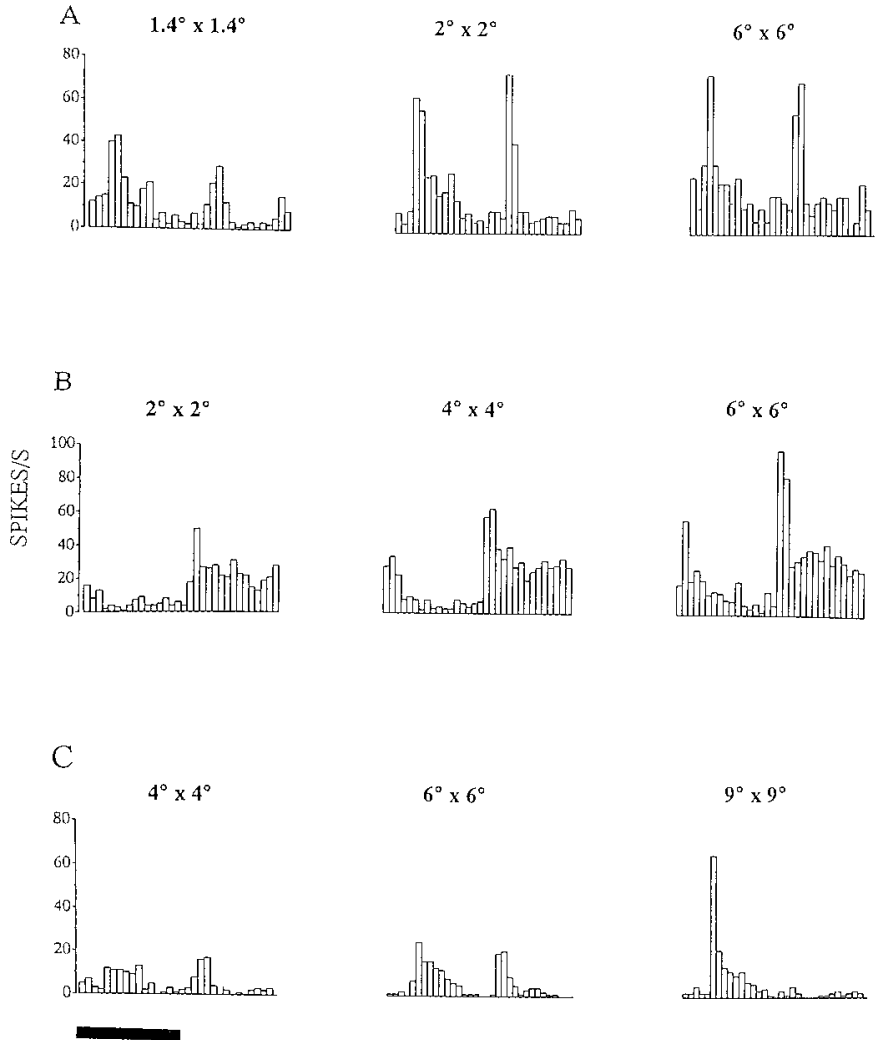

Figure 5. Lack of an inhibitory surround in three $\mathrm{ON}-\mathrm{OFF}$ cells driven by the APB-treated eye. In $A$ (dlgn cell) and $B$ (OT cell), the same response patterns were evident in the PSTHs at all stimulus dimensions; in $C$ (dlgn cell) the pattern changed from ON-OFF to OFF (onset of dark stimulus) when the largest stimulus was used. The PSTHs are based on 20 stimulus presentations; all other conventions are as in Figure 4.

treated retinas, and, as mentioned earlier, this work is now in progress.

The results of the present study also suggest that APB treatment induces alterations in neuronal circuitry of the developing retina other than the maintenance of multistratified ganglion cells and the subsequent ingrowth of bipolar cell axonal terminals. This is indicated by the finding that all of the cells driven by the APB-treated eye lacked a suppressive surround. Unlike in the normal retina, the responses of these neurons did not decrease with the size of flashing stimulus. Because it is commonly assumed that horizontal and amacrine cells are responsible for generating the receptive field surrounds of mature ganglion cells (Wässle and Boycott, 1991), this implies that treating the developing retina with APB might also alter the synaptic organization of these interneurons.

\section{APB treatment of developing retina affects both ON and OFF cells}

In the mature retina, APB has been shown to selectively block the ON pathway when the retina is light adapted (for review, see Schiller, 1992). At the same time, our previous anatomical studies revealed that both $\mathrm{ON}$ and $\mathrm{OFF}$ retinal ganglion cells are affected about equally when the developing retina is treated with this glutamate agonist (Bodnarenko and Chalupa, 1993; Bodnarenko et al., 1995). The present functional results are entirely in accord with these observations, because the incidence of ON and OFF cells was found to be reduced by a nearly equal extent from the normal 50:50 ratio. The lack of selectivity for the ON pathway
A
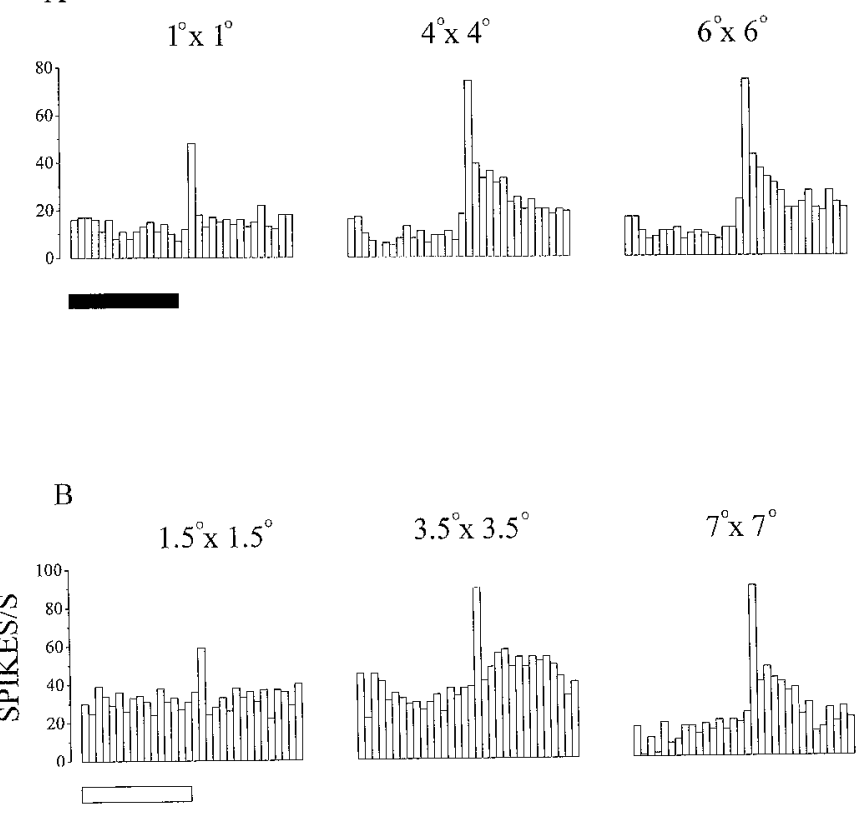

C
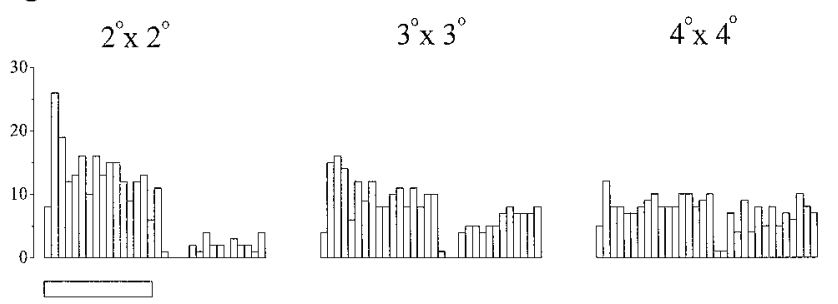

Figure 6. Lack of an inhibitory surround in an ON $(A)$ and an OFF $(B)$ cell driven by the APB-treated eye. In $C$, normal response suppression in an ON cell activated by the control eye with stimuli of increasing size. The stimuli were modulated at $1 \mathrm{~Hz}$ by a half-wave rectified sinusoid below $(A)$ or above $(B, C)$ the mean luminance of $28 \mathrm{~cd} / \mathrm{m}^{2}$. The PSTHs are based on 10 stimulus presentations, the contrast was $100 \%$, and the time bin was $31.3 \mathrm{msec}$.

observed here and in the previous anatomical studies could reflect one of two factors. First, our APB injections undoubtedly blocked the release of glutamate from $\mathrm{ON}$ cone bipolar cells as well as rod bipolar cells. The rod bipolar cells form part of the circuitry for both ON and OFF retinal pathways because these interneurons terminate on AII amacrine cells, which connect with ON cone bipolar cells via gap junctions and with OFF ganglion cells via conventional synapses (Kolb and Famiglietti, 1974; Famiglietti and Kolb, 1976; McGuire et al., 1984, 1986). Thus, under scotopic conditions hyperpolarization of rod bipolar cells by APB in the retina has been shown to completely eliminate visual responses in both $\mathrm{ON}$ and OFF ganglion cells in the adult cat retina (Wässle et al., 1991). In our studies, the direct OFF cone bipolar pathway would be expected to remain functional, but apparently this is not sufficient to induce stratification in the OFF ganglion cells.

It may also be the case that, unlike in the mature retina, $\mathrm{ON}$ as well as OFF cone bipolar cells are APB-sensitive, and such expression is transient in the OFF bipolars. This could be assessed by making patch-clamp recordings from these interneurons 
during the developmental period when APB injections were made in the present study. Recently, we showed by means of such recordings that developing ganglion cells are not sensitive to APB (Liets and Chalupa, 1996). This finding rules out the possibility that the effects documented here could be attributable to a direct influence of this ligand on multistratified ganglion cells, but whether other retinal neurons manifest a transient expression of APB-sensitive receptors remains to be established.

\section{Implications for functional changes at higher levels of the visual system}

The functional utility of segregated $\mathrm{ON}$ and OFF retinal pathways is unknown, yet this appears to be a common feature of all vertebrates. From this perspective, it would be of interest to use behavioral measures to assess the processing of visual information by the APB-treated eye. It would seem reasonable to think that such an approach could reveal some degree of impairment in terms of the ability to discriminate light from dark stimuli and, quite possibly, other visual impairments stemming from reorganized connections at higher levels of the visual system. In particular, it has recently been shown that treating the developing ferret retina with APB disrupts the formation of ON and OFF retinogeniculate sublaminae (Yeung et al., 1997). This may relate to the observations of Wong and Oakley (1996), who found separate waves of $\mathrm{ON}$ and OFF ganglion cell activities in the developing ferret retina during the developmental period when these sublaminae are normally formed in the dlgn. It has also been suggested that the orientation selectivity exhibited by visual cortical cells reflects the sequential innervation pattern of $\mathrm{ON}$ or OFF dlgn cells onto single cortical cells (Chapman et al., 1991). In view of our results, one might expect orientation-tuning properties of some cortical cells to be abnormal after APB treatment of the developing retina. The observations reported here may prove useful for examining the contributions of segregated $\mathrm{ON}$ and OFF retinal channels to the organization of the visual system at higher levels.

\section{REFERENCES}

Bodnarenko SR, Chalupa LM (1993) Stratification of ON and OFF ganglion cell dendrites depends on glutamate-mediated afferent activity in the developing retina. Nature 364:144-146.

Bodnarenko SR, Jeyarasasingam G, Chalupa LM (1995) Development and regulation of dendritic stratification in retinal ganglion cells by glutamate-mediated afferent activity. J Neurosci 15:7037-7045.

Bolz J, Wassle H, Thier P (1984) Pharmacological modulation of on and off ganglion cells in the cat retina. Neuroscience 12:875-885.

Chapman B, Zahs KR, Stryker MP (1991) Relation of cortical cell orientation selectivity to alignment of receptive fields of the geniculocortical afferents that arborize within a single orientation column in ferret visual cortex. J Neurosci 11:1347-1358.

Conway JL, Schiller PH (1993) Laminar organization of tree shrew dorsal lateral geniculate nucleus. J Neurophysiol 50:1330-1342.

Dubin MW, Stark LA, Archer SM (1986) A role for action-potential activity in the development of neuronal connections in the kitten retinogeniculate pathway. J Neurosci 6:1021-1036.
Euler T, Schneider H, Wässle H (1996) Glutamate responses of bipolar cells in the rat retina. J Neurosci 16:2934-2944.

Famiglietti Jr EV, Kolb H (1976) Structural basis for ON- and OFFcenter responses in retinal ganglion cells. Science 194:193-195.

Gargini C, Chalupa LM, Bisti S (1966) Reorganization of receptive field properties after treatment of the developing retina with APB. Soc Neurosci Abstr 22:1725.

Kolb H, Famiglietti EV (1974) Rod and cone pathways in the inner plexiform layer of the cat retina. Science 186:47-49.

Kuffler SW (1953) Discharge patterns and functional organization of mammalian retina. J Neurophysiol 16:37-68.

Lau KC, So KF, Tay D (1990) Effects of visual or light deprivation on the morphology, and the elimination of the transient features during development, of type I retinal ganglion cells in hamsters. J Comp Neurol 300:583-592.

Leventhal AG, Hirsch HV (1983) Effects of visual deprivation upon the morphology of retinal ganglion cells projecting to the dorsal lateral geniculate nucleus of the cat. J Neurosci 3:332-44.

Liets LC, Chalupa LM (1996) The metabotropic glutamate agonist 2-amino-4-phosphonobutyric acid (APB) does not activate currents in postnatal retinal ganglion cells. NeuroReport 7:2873-2877.

Maslim J, Stone J (1988) Time course of stratification of the dendritic fields of ganglion cells in the retina of the cat. Dev Brain Res 44:87-93.

Maslim J, Webster M, Stone J (1986) Stages in the structural differentiation of retinal ganglion cells. J Comp Neurol 254:382-402.

McGuire B, Stevens J, Sterling P (1984) Microcircuitry of bipolar cells in cat retina. J Neurosci 4:2920-2038.

McGuire B, Stevens J, Sterling P (1986) Microcircuitry of beta ganglion cells in the cat retina. J Neurosci 6:907-918.

Muller F, Wässle H, Voigt T (1988) Pharmacological modulation of the rod pathway in the cat retina. J Neurophysiol 59:1657-1672.

Nelson R, Famiglietti Jr EV, Kolb H (1978) Intracellular staining reveals different levels of stratification for on- and off-center ganglion cells in cat retina. J Neurophysiol 41:472-483.

Norton TT, Rager G, Kretz R (1985) ON and OFF regions in layer IV of striate cortex. Brain Res 488:348-352.

Schiller PH (1992) The ON and OFF channels of the mammalian visual system. Prog Retina Eye Res 15:173-195.

Slaughter MM, Miller RF (1981) 2-amino-4-phosphonobutyric acid: a new pharmacological tool for retina research. Science 211:182-185.

Stone J, Fukuda Y (1974) Properties of cat retinal ganglion cells: a comparison of W-cells with X- and Y-cells. J Neurophysiol 37:722-748.

Stryker MP, Zahs KR (1983) ON and OFF sublaminae in the lateral geniculate nucleus of the ferret. J Neurosci 3:1943-1951.

Tootle JS (1993) Early postnatal development of visual function in ganglion cells of the cat retina. J Neurophysiol 69:1645-1660.

Wässle H, Boycott B (1991) Functional architecture of the mammalian retina. Physiol Rev 71:447-480.

Wässle H, Yamashita M, Greferath U, Grunert U, Muller F (1991) The rod bipolar cell of the mammalian retina. Vis Neurosci 7:99-112.

Wong RO, Oakley DM (1996) Changing patterns of spontaneous bursting activity of on and off retinal ganglion cells during development. Neuron 16:1087-1095.

Wong RO, Herrmann K, Shatz CJ (1991) Remodeling of retinal ganglion cell dendrites in the absence of action potential activity. J Neurobiol 22:685-697.

Yeung G, Miller L, Stoddard A, Bodnarenko SR (1997) Role of glutamate-mediated afferent activity in the development of on/off retinal ganglion cell (RGC) morphology in ferrets. Soc Neurosci Abstr 23:640. 